\title{
Feasibility and psychometric properties of the German 12-item WHO Disability Assessment Schedule (WHODAS 2.0) in a population-based sample of patients with myocardial infarction from the MONICA/KORA myocardial infarction registry
}

Inge Kirchberger ${ }^{1,2^{*}}$, Kathrin Braitmayer ${ }^{3}$, Michaela Coenen ${ }^{3}$, Cornelia Oberhauser ${ }^{3}$ and Christa Meisinger $^{1,2}$

\begin{abstract}
Background: The World Health Organization Disability Assessment Schedule 2.0 (WHODAS 2.0) provides a standardized assessment of functioning and disability in individuals with any kind of disease. So far, data on feasibility and psychometric properties of the 12-item WHODAS 2.0 in patients with acute myocardial infarction (AMI) are not available. Thus, the objective of this study was to investigate feasibility and psychometric properties of this questionnaire in a population-based sample of persons with AMI.

Methods: The sample consisted of 2077 persons (age 35-85 years) with AMl from the population-based MONICA/KORA Myocardial Infarction Registry, Augsburg, Germany, who responded to a postal follow-up survey in 2011. Feasibility was assessed by the number of missing WHODAS 2.0 items and analyzed using multivariate logistic regression modeling. Psychometric properties were determined using Rasch analysis. It included testing of unidimensionality, monotonicity and local independency, Partial Credit Model (PCM) fitting, and testing for Differential Item Functioning (DIF). Concurrent validity was tested by a linear additive model predicting the WHODAS disability score based on a number of independent variables.

Results: For $96 \%$ of the subjects, the WHODAS disability score could be computed. Incomplete questionnaires were significantly more common in older persons (Odds ratio (OR) 1.03, 95\% confidence interval (Cl) 1.01-1.05) and persons with $\mathrm{bad} / \mathrm{very}$ bad self-rated health (OR $2.55,95 \% \mathrm{Cl} 1.28-5.06)$. The assumptions of Rasch modeling were fulfilled. The PCM revealed disordered thresholds for nine of the 12 items. However, it was possible to achieve a correct order of thresholds by collapsing the five response options to three. The item thresholds covered the whole range of the continuum, indicating that items are appropriate to differentiate between persons across the whole continuum of disability. No DIF was detected for any of the tested variables such as age, sex, and education. Significantly higher disability scores were found in persons with comorbidities and impaired overall health status, confirming concurrent validity.

(Continued on next page)
\end{abstract}

\footnotetext{
* Correspondence: inge.kirchberger@helmholtz-muenchen.de

1 MONICA/KORA Myocardial Infarction Registry, Central Hospital of Augsburg, Stenglinstr. 2, Augsburg 86156, Germany

2Institute of Epidemiology II, Helmholtz Zentrum München, German Research Center for Environmental Health $(\mathrm{GmbH})$, Ingolstädter Landstr. 1, Neuherberg 85764, Germany

Full list of author information is available at the end of the article
}

() Biomed Central

(c) 2014 Kirchberger et al.; licensee BioMed Central Ltd. This is an Open Access article distributed under the terms of the Creative Commons Attribution License (http://creativecommons.org/licenses/by/4.0), which permits unrestricted use, distribution, and reproduction in any medium, provided the original work is properly credited. The Creative Commons Public Domain Dedication waiver (http://creativecommons.org/publicdomain/zero/1.0/) applies to the data made available in this article, unless otherwise stated. 
(Continued from previous page)

Conclusions: The 12-item WHODAS 2.0 is a feasible, nonbiased, and valid instrument for application in persons with AMI. Shortcomings refer to unordered thresholds of most items. Further studies are required in order to confirm these findings.

Keywords: WHODAS, Disability, Myocardial infarction, Rasch analysis, Psychometric properties

\section{Background}

Functioning and disability are increasingly recognized as relevant outcomes of studies on patients with chronic health conditions [1]. The World Health Organization Disability Assessment Schedule 2.0 (WHODAS 2.0) has been developed to facilitate a standardized assessment of the consequences of any kind of disease that has an impact on individuals' functioning and disability $[2,3]$. The questionnaire is conceptually based on the International Classification of Functioning, Disability and Health (ICF) [4] which addresses functioning and disability as concepts independent from medical diagnoses and neutral in respect of its etiology. Reflecting a biopsychosocial perspective of functioning and disability, the ICF considers impairments of body structures and body functions, limitations in activities and restrictions in participation, as well as influencing contextual factors such as personal and environmental factors.

The WHODAS 2.0 questionnaire is available in different forms depending on the number of items $(6,12,24$, $12+24$, and 36 items), the mode of administration (selfadministered or interview), and the respondent (subject, clinician, caregiver) [5]. The 36-item WHODAS 2.0 contains six domains: understanding and communication, getting around, self-care, getting along with people, life activities, and participation in society. It has been tested for its psychometric properties in a number of studies with population samples [6] and persons with different health conditions [7-10].

The 12-item WHODAS 2.0 covers all six domains of the 36-item form. Two different versions of the 12-item WHODAS 2.0 exist, the original version [6] and a revised version with five items replaced. The original version was reported to correlate highly $(r=0.95)$ with the 36 -item form and to explain more than $90 \%$ of the variation of the 36-item WHODAS 2.0 [6], while the currently used revised version was reported to explain $81 \%$ of that variance (http://www.who.int/classifications/icf/ whodasii/en/index3.html). It takes about five minutes to complete the 12-item form. Thus, this form is expected to be a feasible screening instrument specifically for population surveys. However, an investigation of the feasibility of the WHODAS 2.0 self-administered 12-item form is lacking. Moreover, in contrast to the 36-item WHODAS, for the 12-item form studies on its psychometric properties are scarce so far. The available studies are limited to the general population [11], older people [12], and patients with depression [13-15].

Persons with coronary heart diseases (CHD) and its complications such as acute myocardial infarction (AMI) are at risk of developing disability in the long-term course of the disease $[16,17]$. Available studies that investigate functioning and disability associated with CHD often had a restricted assessment approach. For instance, the physical function subscale of the Short Form 36 Health Survey (SF-36) [18,19], the EuroQol 5D (EQ5D) [18], single questions selected from the Functional Health Scale $[17,20,21]$, or self-developed questions $[16,22]$ were applied to assess disability in persons with AMI. Thus, it would be useful to have a standardized, internationally accepted instrument covering disability from the biopsychosocial perspective to provide a feasible, reliable, and valid measurement of disability in patients with AMI.

Consequently, the objective of this study was to investigate feasibility and psychometric properties of the 12-item self-administered WHODAS 2.0 in a large populationbased sample of persons with AMI.

\section{Methods}

In order to examine feasibility and psychometric properties of the 12-item self-administered WHODAS 2.0 in persons with AMI we carried out multivariate logistic regression modeling and Rasch analysis using data of the population-based Augsburg Myocardial Infarction Registry. The registry was implemented in 1984 as part of the WHO-MONICA (Monitoring Trends and Determinants in Cardiovascular Disease) project [23]. After the termination of MONICA in 1995, the registry became part of the framework of KORA (Cooperative Health Research in the Region of Augsburg, Germany). Since 1984, all cases of coronary deaths and non-fatal AMI of the 25-74. year old study population in the city of Augsburg and the two adjacent counties (about 600,000 inhabitants) have been continuously registered. Data sources for hospitalized patients include eight hospitals within the study region and two hospitals in the adjacent areas. Approximately $80 \%$ of all AMI cases of the study region are treated in the study region's major hospital, Klinikum Augsburg, a tertiary care centre offering invasive and interventional cardiovascular procedures, as well as heart surgery facilities [23,24]. Methods of case finding, 
diagnostic classification of events, and data quality control have been described elsewhere [23,24]. Routinely, patients are interviewed during their hospital stay by trained study nurses after transfer from the intensive care unit using a standardized questionnaire. The interviews include demographic data, risk factors, and comorbidities. Further data on clinical variables, comorbidities, treatment, and in-hospital course are determined by chart review.

The study was approved by the Ethics committee of the Bavarian chamber of physicians and performed in accordance with the Declaration of Helsinki. Participants gave written informed consent prior to study inclusion.

\section{Sample}

The target sample consisted of all 3740 patients with AMI included in the MONICA/KORA Myocardial Infarction Registry, Augsburg, Germany, in the years 2000 to 2008 who were alive on 1 July 2011. Of these, 1266 persons have previously declined further participation. A postal questionnaire was sent to the remaining 2474 persons, including questions on the current health status, comorbidities, medication, and health care, as well as the German version of the 12-item WHODAS 2.0 (revised version). Reminders were sent to 1194 persons who have not responded by September 2011. Persons who still failed to respond were reminded by telephone. Thirty persons could not be reached because they had died, 63 declined their participation, 38 were not available, three were not known at the available address, and 243 could not be reached by telephone for other reasons (e.g., no telephone connection, not reachable). The final sample consisted of 2077 men and women aged 35-85 years with first or recurrent AMI who responded to the questionnaire. Compared with the persons who could not participate for any reason, this sample had a similar distribution of sexes (22.2\% versus $23.0 \%$ women), but a slightly higher mean age $(66.6 \pm 9.5$ years versus $64.0 \pm 11.9$ years $)$.

\section{Data used for analyses}

The following data and measures were used for the data analyses:

(1) Data obtained from patient interview and/or chart review during the hospital stay, namely sex, age at infarction, education according to the German school system (dichotomized into $<=9$ years vs. $>9$ years school education), marital status (married vs. not married), history of hypertension, diabetes, angina pectoris, hyperlipidemia, smoking (current smoker, ex-smoker, never smoker), previous AMI, AMI type (ST-segment elevation MI, non-ST-segment elevation MI, bundle branch block), and reperfusion treatment (thrombolysis, bypass surgery, percutaneous coronary intervention with or without stenting, no reperfusion therapy).

(2) Data of a postal follow-up questionnaire requesting information on current age and re-infarction and diabetes. Comorbidities were assessed using a modified version of the Self-administered Comorbidity Questionnaire [25], which requests information on the presence of 13 chronic health conditions. In addition, patients were asked to name any other diseases they had. A variable reflecting the sum of all named comorbidities was built and dichotomized into "no comorbidities" and "at least one comorbidity". Furthermore, overall health status was measured by the question "How do you rate your general health state in the past 30 days?" Response options were "very good", "good", "moderate", "bad", and "very bad". For the data analyses, the response options "very good" and "good", as well as "bad" and "very bad", were collapsed.

(3) WHODAS 2.0 12-item self-administration version as additional part of the postal questionnaire. For each item, respondents had to indicate the level of difficulty experienced during the previous 30 days using a five-point scale (none, mild, moderate, severe, extreme/cannot do). According to the standard scoring algorithm, a total score was calculated for persons who completed at least 10 of the 12 questions by summing up all items, while up to two missing items were replaced by the mean score of the remaining items [5].

\section{Data analysis}

Descriptive analyses were carried out to describe the sample in terms of socio-demographic and clinical characteristics. Absolute and relative frequencies of the responses to each WHODAS 2.0 item were calculated.

\section{Feasibility}

Feasibility of the WHODAS 2.0 was determined by the number of missing items. Associations of incomplete WHODAS 2.0 questionnaires (1 to 12 missing items) with age, sex, education, marital status, presence of comorbidities and overall health status rating were first illustrated by descriptive statistics and tested using $\mathrm{Chi}^{2}$-test and then analyzed applying multivariate logistic regression modeling. Odds ratios (OR) and their 95\% confidence intervals $(\mathrm{CI})$ were reported in order to describe differences between the persons who had not or not fully completed the WHODAS 2.0 and those who returned a questionnaire without missing items. Analyses were performed using SAS version 9.2 (SAS Institute Inc., Cary, North Carolina). 


\section{Psychometric properties}

Psychometric properties were examined by using Rasch analysis [26]. We only included those patients for whom a 12-item sum score could be calculated [5]. Therefore, the data of 1995 patients were considered for further analysis. Rasch models assume an underlying latent trait, which in the case of the WHODAS 2.0 is disability. On this trait both item difficulty and person ability are located [26]. We chose a Partial Credit Model (PCM) (also called Polytomous Rasch Model) due to our set of ordinal, polytomous items.

Rasch analysis was performed in the following steps:

(1) Testing of model assumptions: We tested the model assumptions unidimensionality, monotonicity, and local independency.

Unidimensionality was examined using bifactor analysis on the polychoric correlation matrix [27,28]. Within bifactor analysis the existence of one general factor and multiple independent group factors are presumed. High loadings on the general factor exceeding those of the group factors for all items indicate an underlying unidimensional latent trait. The number of factors considered in the bifactor analysis was determined by permuted parallel analysis [29].

Monotonicity was explored for each item by reviewing graphs of the item's distribution conditional on average "rest-scores". These scores were calculated for each item as the total raw score of all the remaining non-missing items divided by their number. If there is a consistent trend that persons with higher rest-scores are more likely to have more problems in the given item, then monotonicity can be assumed.

Local independency was examined based on the residual correlations among items resulting from a single-factor analysis [30]. High residual correlations suggest that the response to one question influences the response to another.

(2) Computing and fitting of the Rasch model: After evaluating the model assumptions the PCM was fitted. When calculating a PCM the item location, or the overall item difficulty, is provided for every item [31]. Furthermore, item thresholds for each item are computed, indicating the location on the latent trait where the item best discriminates between persons [31-34]. In case of unordered thresholds the response options had to be collapsed until they were in the correct order before proceeding with tests on the model. Should collapsing be necessary, we decided to collapse all items identically for a better comparability among the items.

Finally, we examined item fit based on (unweighted) outfit and (weighted) infit mean squares and created graphics to be able to better interpret these measures [26]. Both mean squares are interpreted in the same way: 1) mean squares close to 1 indicate good item fit;
2) mean squares much larger than one indicate underfit (i.e., the observed data varies much more than can be explained by the model - which constitutes a severe violation of the model); 3) mean squares much smaller than 1 indicate overfit (i.e., the data varies much less than would be expected based on the model - which is usually accepted). Different cut-offs for identifying too large and too small mean squares can be found in the literature $[26,35,36]$. Usually, values between 0.70 and 1.3 are considered reasonable, but the cut-offs depend on the sample size, the number of items, and their number of response options. Therefore, to be able to better judge on item fit, we created graphics comparing 1) expected probabilities for responding above a certain threshold with 2) the observed response frequencies for groups of persons with close ability estimates.

Rasch analysis was performed using $\mathrm{R}$ software [37] and computed with the $\mathrm{R}$ package eRm [38].

(3) Testing for Differential Item Functioning (DIF): We tested DIF for sex, age (above or below 65), education, marital status, presence of comorbidities, overall health status, and smoking status. Due to the large sample size, change in McFadden's pseudo $R^{2}(r<=0.02)$ was chosen as the criterion for flagging. If items show DIF they are a potential cause for bias in person measurement. This is the case if different groups (e.g., older and younger patients) respond in a different way despite equal levels of the underlying characteristic being measured [31]. For testing DIF we used the $\mathrm{R}$ package lordif [39].

(4) Assessment of concurrent validity: For the final Rasch model person ability was transformed into a score ranging from 0 to 100 (with 0 corresponding to perfect functioning/no disability) in order to facilitate the interpretation of group differences. A linear additive model [40] was estimated predicting the value of this disability score based on sex, age, education, marital status, presence of comorbidities, and overall health status as independent variables.

Age was modeled in a flexible, non-parametric way using P-splines. Concurrent validity can be assumed if persons, for example, with comorbidities or worse overall health status have a higher expected level of disability (i.e., higher score values) compared to those without comorbidities and those rating their health as good or very good. For estimating the linear additive model we used the $\mathrm{R}$ package mgcv [40].

\section{Results}

Socio-demographic and clinical characteristics of the sample are presented in Table 1 . The absolute and relative frequencies of the WHODAS 2.0 items can be found in Table 2 . 
Table 1 Sample characteristics

\begin{tabular}{|c|c|c|}
\hline & $\begin{array}{l}\text { Total sample } \\
(n=2077)\end{array}$ & $\begin{array}{l}\text { Sample used for } \\
\text { psychometric } \\
\text { analysis }(n=1995)\end{array}$ \\
\hline Gender [female], n (\%) & $461(22.2)$ & $438(22.0)$ \\
\hline Age [years], mean/SD & $66.6 / 9.5$ & $66.5 / 9.5$ \\
\hline \multicolumn{3}{|l|}{ Education, n (\%) } \\
\hline School education $<=9$ years & $1393(67.1)$ & $1344(67.4)$ \\
\hline School education $>9$ years & $602(29.0)$ & $593(29.7)$ \\
\hline Missing data & $82(3.9)$ & $58(2.9)$ \\
\hline \multicolumn{3}{|l|}{ Marital status, n (\%) } \\
\hline Married & $1607(77.4)$ & $1554(77.9)$ \\
\hline Unmarried & $455(21.9)$ & $428(21.4)$ \\
\hline Missing data & $15(0.7)$ & $13(0.7)$ \\
\hline $\begin{array}{l}\text { Time since infarction [years], } \\
\text { mean/SD }\end{array}$ & $6.5 / 2.4$ & $6.5 / 2.4$ \\
\hline Reinfarction, n (\%) & $188(9.1)$ & $176(8.8)$ \\
\hline \multicolumn{3}{|l|}{ Infarction type, n (\%) } \\
\hline ST-segment elevation MI & $796(38.3)$ & $769(38.6)$ \\
\hline Non-ST-segment elevation Ml & $1139(54.8)$ & $1090(54.6)$ \\
\hline Bundle branch block & $103(5.0)$ & $100(5.0)$ \\
\hline Missing data & $39(1.9)$ & $36(1.8)$ \\
\hline \multicolumn{3}{|l|}{ Acute treatment, n (\%) } \\
\hline No reperfusion treatment & $249(12.0)$ & $233(11.7)$ \\
\hline Coronary artery bypass grafting & $312(15.0)$ & $301(15.1)$ \\
\hline PTCA ${ }^{a}$ without stenting & $82(4.0)$ & $77(3.9)$ \\
\hline PTCA with stenting & $1390(66.9)$ & $1342(67.3)$ \\
\hline Thrombolysis & $44(2.1)$ & $42(2.1)$ \\
\hline \multicolumn{3}{|l|}{ Diabetes, n (\%) } \\
\hline Yes & $517(24.9)$ & $488(24.5)$ \\
\hline No & $1545(74.4)$ & $1507(75.5)$ \\
\hline Missing data & $15(0.7)$ & - \\
\hline \multicolumn{3}{|l|}{ Angina pectoris, n (\%) } \\
\hline Yes & $352(17.0)$ & $330(16.5)$ \\
\hline No & 1725 (83.0) & 1665 (83.5) \\
\hline \multicolumn{3}{|l|}{ Hypertension, n (\%) } \\
\hline Yes & $1593(76.7)$ & $1516(76.0)$ \\
\hline No & $484(23.3)$ & $479(24.0)$ \\
\hline \multicolumn{3}{|l|}{ Hyperlipidemia, n (\%) } \\
\hline Yes & $1511(72.8)$ & $1523(76.3)$ \\
\hline No & $566(27.2)$ & $472(23.7)$ \\
\hline \multicolumn{3}{|l|}{ Smoking, n (\%) } \\
\hline Current smoker & $723(34.8)$ & $701(35.1)$ \\
\hline Ex-smoker & 670 (32.3) & $642(32.2)$ \\
\hline Never smoker & $646(31.1)$ & $615(30.8)$ \\
\hline Missing data & $38(1.8)$ & $37(1.9)$ \\
\hline
\end{tabular}

Table 1 Sample characteristics (Continued)

\begin{tabular}{lll}
\hline $\begin{array}{ll}\text { Number of comorbidities, } \mathrm{n}(\%) \\
0\end{array}$ & $511(24.6)$ & $498(25.0)$ \\
$>0$ & $1537(75.4)$ & $1479(75.0)$ \\
Missing data & $29(1.4)$ & $18(0.9)$ \\
Health status rating, $\mathrm{n}(\%)$ & & \\
Very good & $190(9.2)$ & $189(9.5)$ \\
Good & $884(42.6)$ & $866(43.4)$ \\
Moderate & $759(36.5)$ & $727(36.4)$ \\
Bad & $179(8.6)$ & $171(8.6)$ \\
Very bad & $38(1.8)$ & $38(1.9)$ \\
Missing data & $28(1.3)$ & $4(0.2)$ \\
aPercutanous translumial coronary angioplasty. &
\end{tabular}

\section{Feasibility}

From the 2077 respondents, 2055 (98.9\%) completed at least one item from the WHODAS 2.0. Most patients ( $\mathrm{n}=$ $1802,86.8 \%)$ answered all questions, 158 patients $(7.6 \%)$ left one question blank. Two or three items were missing for 53 patients $(2.6 \%)$, and 42 patients $(2.0 \%)$ had four to 11 missing items. Items which were most frequently not answered were "Learning a new task" ( $\mathrm{n}=78,3.8 \%$ ), "Household responsibilities" ( $\mathrm{n}=74,3.6 \%$ ), and "Community activities" ( $\mathrm{n}=74,3.6 \%)$. The association between age, sex, education, marital status, presence of comorbidities, selfrated health status, and the completeness of the WHODAS 2.0 was examined in a bivariate analysis. Persons who did not complete one to 12 items of the WHODAS 2.0 were compared to those who completed all items. Figure 1 shows that incomplete WHODAS 2.0 questionnaires were significantly more often found in women, older persons, and persons with poor education or bad health status.

Further, these six variables were tested for their association with completeness of WHODAS 2.0 questionnaires in multivariate logistic regression models. No interaction effect between current age and sex was found. Table 3 shows the results of the full model including all six independent variables. Older persons and persons with bad/ very bad health status were more likely to have missing WHODAS 2.0 items compared with younger persons or very good/good health status, respectively.

\section{Psychometric properties}

(1) Model assumptions: All items showed high loadings on the general factor (mean: 0.82; range: 0.67-0.95, percentage of variance accounted for by the general factor: 67.3\%) and loaded higher on the general factor compared to the group factors supporting the assumption of unidimensionality. Monotonicity was graphically confirmed. A general trend of persons with higher restscores showing more difficulties in the respective item 
Table 2 Frequencies of the response options in the sample considered for Rasch analysis $(n=1995)$

\begin{tabular}{|c|c|c|c|c|c|c|}
\hline $\begin{array}{l}\text { In the past } 30 \text { days, how much difficulty did } \\
\text { you have in: }\end{array}$ & $\begin{array}{l}\text { None } \\
\text { n (\%) }\end{array}$ & $\begin{array}{l}\text { Mild } n \\
(\%)\end{array}$ & $\begin{array}{l}\text { Moderate } \\
\text { n (\%) }\end{array}$ & $\begin{array}{l}\text { Severe } \\
\text { n (\%) }\end{array}$ & $\begin{array}{l}\text { Extreme/cannot do } \\
\text { n (\%) }\end{array}$ & $\begin{array}{l}\text { Not answered } \\
\mathrm{n}(\%)\end{array}$ \\
\hline Standing for long periods such as 30 minutes & $1023(51.3)$ & $326(16.3)$ & $295(14.8)$ & $208(10.4)$ & $118(5.9)$ & $25(1.3)$ \\
\hline Taking care of your household responsibilities & $1155(57.9)$ & $325(16.3)$ & $295(14.8)$ & $103(5.2)$ & $76(3.8)$ & $41(2.1)$ \\
\hline $\begin{array}{l}\text { Learning a new task, for example, learning how } \\
\text { to get to a new place }\end{array}$ & $1472(73.8)$ & $259(13.0)$ & $126(6.3)$ & $51(2.6)$ & $55(2.8)$ & $32(1.6)$ \\
\hline $\begin{array}{l}\text { How much of a problem did you have in joining } \\
\text { in community activities (e.g., festivities, religious } \\
\text { or other activities) in the same way as anyone } \\
\text { else can }\end{array}$ & $1270(63.7)$ & $268(13.4)$ & $230(11.5)$ & $113(5.7)$ & $83(4.2)$ & $31(1.6)$ \\
\hline $\begin{array}{l}\text { How much have you been emotionally affected } \\
\text { by your health condition }\end{array}$ & $550(27.6)$ & $597(29.9)$ & $492(24.7)$ & $249(12.5)$ & $78(3.9)$ & $29(1.5)$ \\
\hline Concentrating on doing something for 10 minutes & $1471(73.7)$ & $283(14.2)$ & $148(7.4)$ & $57(2.9)$ & $22(1.1)$ & $14(0.7)$ \\
\hline $\begin{array}{l}\text { Walking a long distance such as a kilometer or } \\
\text { equivalent }\end{array}$ & $995(49.9)$ & $275(13.8)$ & $253(12.7)$ & $234(11.7)$ & $219(11.0)$ & $19(1.0)$ \\
\hline Washing your whole body & $1638(82.1)$ & $144(7.2)$ & $110(5.5)$ & $46(2.3)$ & $55(2.8)$ & $2(0.1)$ \\
\hline Getting dressed & $1617(81.1)$ & $178(8.9)$ & $114(5.7)$ & $39(2.0)$ & $40(2.0)$ & $7(0.4)$ \\
\hline Dealing with people you do not know & $1672(83.8)$ & $163(8.2)$ & $103(5.2)$ & $37(1.9)$ & $15(0.8)$ & $5(0.3)$ \\
\hline Maintaining a friendship & $1674(83.9)$ & $154(7.7)$ & $93(4.7)$ & $48(2.4)$ & $21(1.1)$ & $5(0.3)$ \\
\hline Your day-to-day work/school & $1176(58.9)$ & $346(17.3)$ & $270(13.5)$ & $99(5.0)$ & $86(4.3)$ & $18(0.9)$ \\
\hline
\end{tabular}

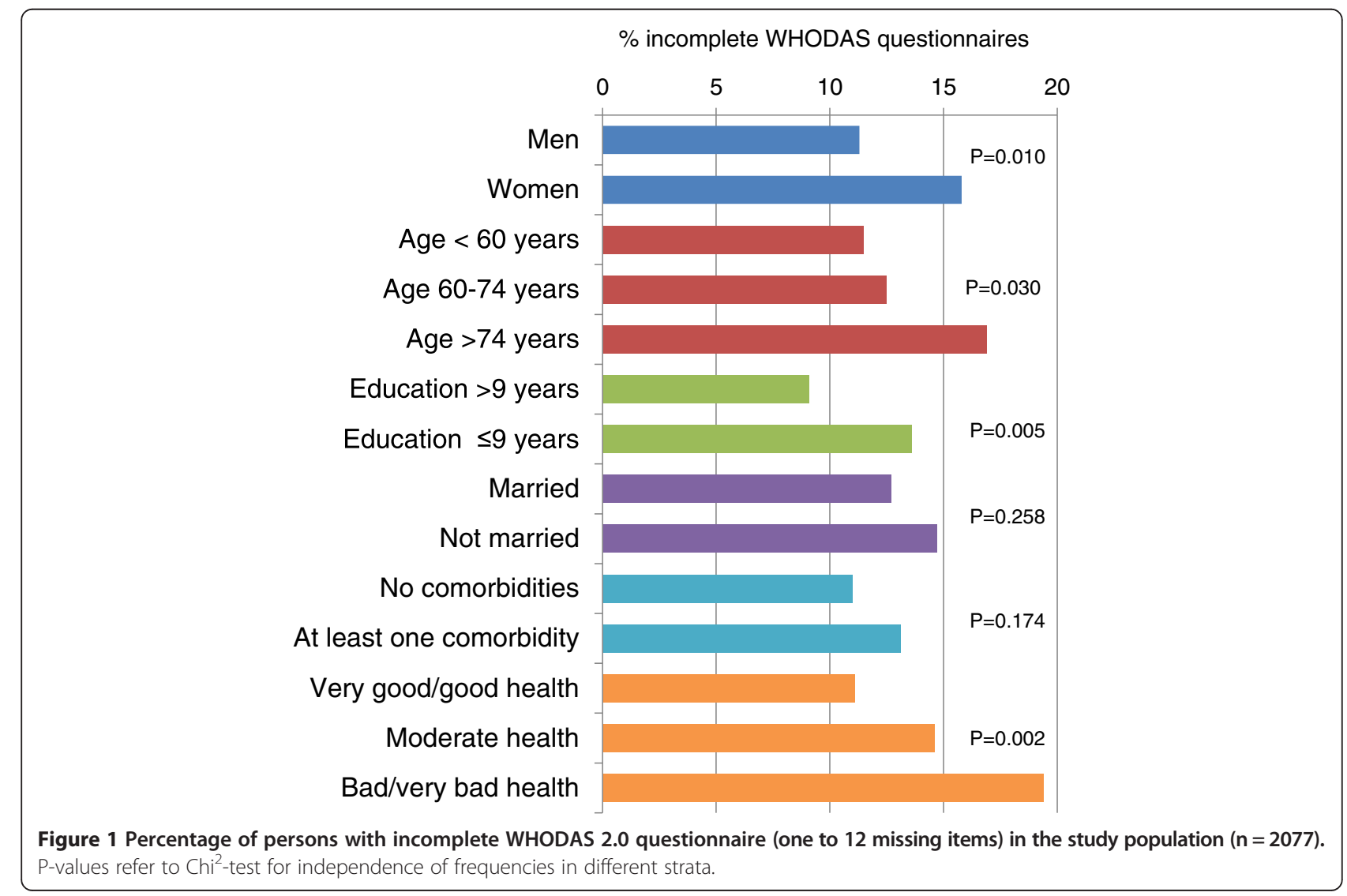




\begin{tabular}{|c|c|c|c|}
\hline Full model & $\begin{array}{l}\text { Odds } \\
\text { ratio }\end{array}$ & $\begin{array}{l}95 \% \text { confidence } \\
\text { interval }\end{array}$ & $p$-value \\
\hline Sex (male) & 0.73 & $0.51-1.04$ & 0.085 \\
\hline Age (continuous) & 1.03 & $1.01-1.05$ & 0.001 \\
\hline Low education & 1.38 & $0.96-1.98$ & 0.078 \\
\hline Married & 1.09 & $0.74-1.60$ & 0.660 \\
\hline Presence of comorbidities & 0.96 & $0.67-1.37$ & 0.815 \\
\hline Very bad/bad health status* & 2.55 & $1.28-5.06$ & 0.008 \\
\hline Moderate health status* & 1.91 & $0.97-3.77$ & 0.062 \\
\hline
\end{tabular}

*Compared to very good/good health status.

was found. We calculated residual correlations among all items based on a single-factor analysis in order to check for possible local dependency. The residual correlations were $r<=0.2$ for all but two correlations $(r=0.31$ for "Maintaining friendship" and "Dealing with unknown people," and $r=0.23$ for "Concentrating" and "Dealing with unknown people").

(2) Computing and fitting of the PCM: The PCM calculated with the original variables revealed unordered thresholds for all but three items ("Concentrating", "Standing", "Being emotionally affected"). Therefore, all items were collapsed based on the collapsing strategy 01122 (0="None;" 1="Mild" and "Moderate;" 2="Severe" and "Extreme/cannot do") and the model re-estimated. The resulting distribution of person abilities, item difficulties, and item thresholds are presented in Figure 2.

Table 4 additionally contains the outfit and infit mean squares. Most of them are very close to one, while five items show slight to moderate overfit and one item ("Learning a new task") shows slight underfit. Figure 3, however, visualizes that the observed frequencies are very close to the expected probabilities for all items, even for "Learning a new task". If there are larger differences, the curve of observed frequencies is steeper, which corresponds to the definition of overfit.

(3) Testing for DIF: No DIF was detected for any of the variables (sex, age, education, marital status, presence of comorbidities, overall health status, and smoking status) in the PCM with the collapsed response options.

(4) Assessment of concurrent validity: For the PCM with the collapsed response options person ability was transformed into a score ranging from 0 to 100 (with 0 corresponding to perfect functioning/no disability). The results from the linear additive model predicting the value of this disability score based on sex, age, education, marital status, presence of comorbidities, and overall health status as independent variables are presented in Table 5 and Figure 4. Table 5 shows that persons with comorbidities or worse overall health status (i.e., higher score values) had worse functioning/more disability compared to those without comorbidities and rated their health as good or very good, indicating high concurrent validity.

Figure 4 shows the nonlinear effect of age (solid line) resulting from the linear additive model and 95\% credible intervals (dashed lines). For age the effect is almost constant up to an age of 68, after which increasingly higher score values are expected, i.e., more disability.

\section{Discussion}

Our study investigated feasibility and psychometric properties of the revised, currently used 12-item self-administered WHODAS 2.0 in a population-based sample of 2077 German patients with AMI. The questionnaire demonstrated good feasibility with only $1 \%$ of the respondents who did not complete the questionnaire at all. Of the respondents $96 \%$ answered at least 10 items, which are required to calculate the WHODAS disability score according to the standard scoring rules [5]. So far only one paper has reported on the feasibility of the revised WHODAS 2.0 12-item version. In a sample of the Australian general population $0.2 \%$ had missing data in one or more WHODAS 2.0 items administered by interview [11]. However, these results are hardly comparable with our study as they differ regarding the mode of administration (interview versus self-administered) and characteristics of the study population (age, health status, country of origin) [41]. Our study is the first comprehensive report on the feasibility of the 12 -item version of the WHODAS 2.0 being self-administered in a sample of patients with AMI with a mean age of 67 years and a high number of persons with poor education. The proportion of $96 \%$ of usable questionnaires was comparable or even higher than for other health questionnaires, e.g., the Short-Form 12 Health Survey (SF-12), applied in elderly persons with cardiovascular diseases [42-44]. One reason for the higher proportion of usable questionnaires in contrast to other questionnaires is the standard scoring algorithm of the WHODAS 2.0, which allows a substitution of up to two missing items by the mean score of the remaining items. Our finding that the completeness of WHODAS 2.0 decreases with rising age and is inversely associated with poor health state is consistent with a number of previous studies using other questionnaires $[41,43,45]$. However, the knowledge about differential nonresponse is crucial for study planning and analyses as it may affect statistical power by reducing sample size and cause selection biases or non-differential information biases [46]. Applying the interview version of a questionnaire instead of postal self-administration can improve response rates and reduce missing data [41]. In addition, methods to handle missing data, such as multiple imputation techniques, were recommended in order to quantify potential biases $[41,47]$. 


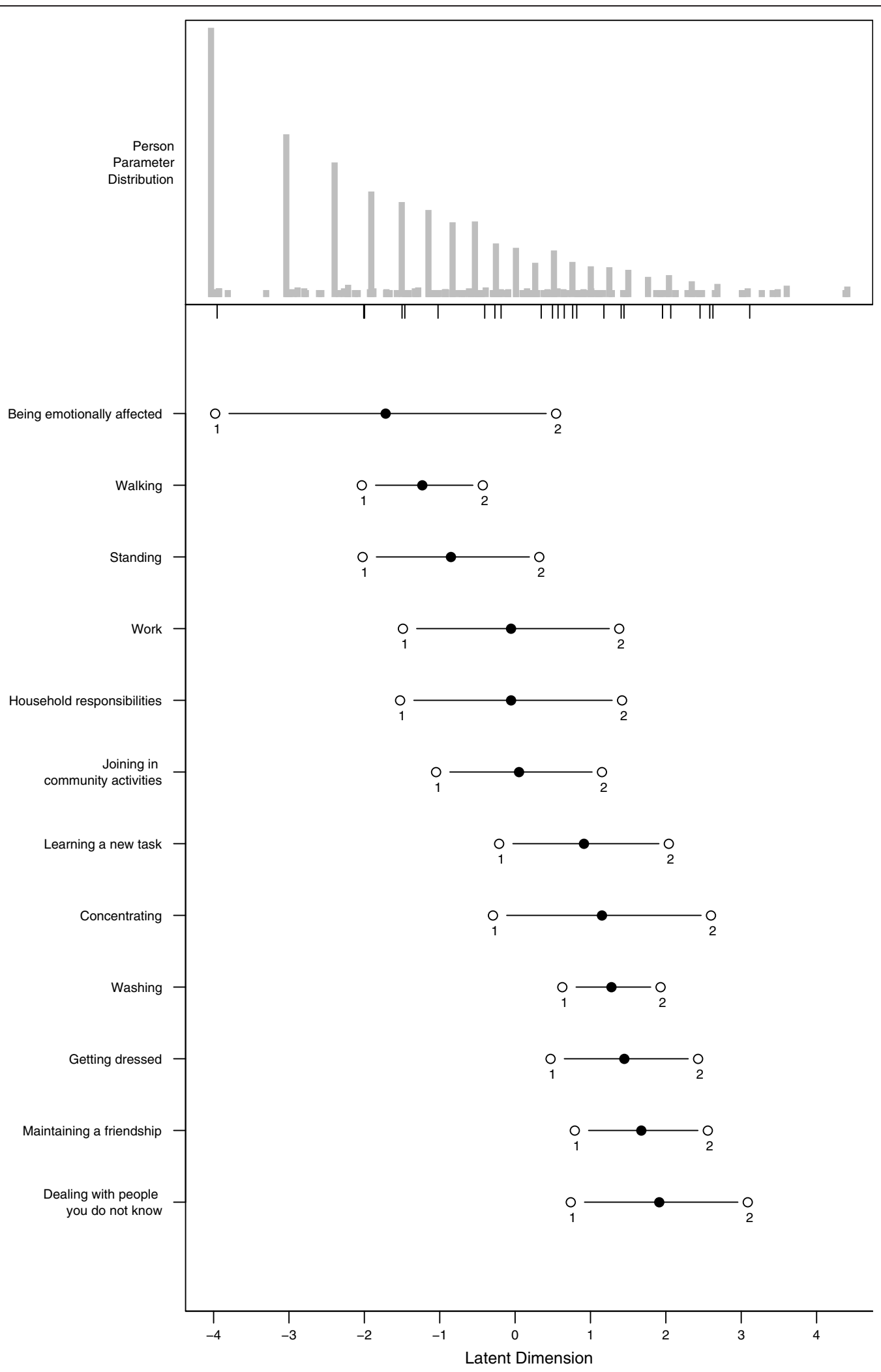

Figure 2 Person-item-map. 
Table 4 Item locations, item thresholds, and outfit and infit mean squares

\begin{tabular}{|c|c|c|c|c|c|}
\hline Item & Location & Threshold 1 & Threshold 2 & $\begin{array}{l}\text { Outfit mean } \\
\text { squares }\end{array}$ & $\begin{array}{l}\text { Infit mean } \\
\text { squares }\end{array}$ \\
\hline Standing & -0.826 & -1.998 & 0.347 & 0.870 & 0.902 \\
\hline Household responsibilities $^{+}$ & -0.028 & -1.500 & 1.445 & 0.610 & 0.693 \\
\hline Learning a new task ${ }^{-}$ & 0.940 & -0.186 & 2.065 & 1.277 & 1.127 \\
\hline Joining in community activities ${ }^{+}$ & 0.078 & -1.023 & 1.178 & 0.749 & 0.819 \\
\hline Being emotionally affected & -1.692 & -3.953 & 0.570 & 1.000 & 1.007 \\
\hline Concentrating & 1.178 & -0.268 & 2.625 & 1.025 & 1.039 \\
\hline Walking & -1.206 & -2.008 & -0.403 & 1.094 & 1.113 \\
\hline Washing $^{+}$ & 1.304 & 0.652 & 1.956 & 0.646 & 0.766 \\
\hline Getting dressed $^{+}$ & 1.475 & 0.496 & 2.454 & 0.752 & 0.787 \\
\hline Dealing with people you do not know & 1.938 & 0.764 & 3.112 & 1.103 & 1.136 \\
\hline Maintaining a friendship & 1.700 & 0.818 & 2.582 & 1.131 & 1.149 \\
\hline Work $^{+}$ & -0.028 & -1.463 & 1.407 & 0.578 & 0.650 \\
\hline
\end{tabular}

${ }^{+}$Item showing slight to moderate overfit.

- Item showing slight underfit.

In terms of the analysis of psychometric properties we showed that the 12-item WHODAS 2.0 fulfilled the assumptions of Rasch modeling. The confirmation of unidimensionality is consistent with Luciano et al. [13] who analysed data of Spanish patients with major depression using exploratory principal component and subsequent confirmatory factor analysis. Sousa et al. [12] examined unidimensionality of the WHODAS 2.0 in elderly people living in seven low- and middle-income countries and showed that principle component analysis gave rise to a one-factor solution in most countries. In the study from Andrews et al. [11] a second-order one-factor solution with six first-order factors was the best-fitting model for the Australian general population.

In our study, the PCM revealed disordered thresholds for nine of the 12 items, whereas Luciano et al. [15] found that all items of the WHODAS 2.0 discriminated well in their study population of patients with a firsttime diagnosis of major depression. Difficulties in differentiating between the five response options, which may be particularly pronounced in our elderly and poorly educated population, can be a potential reason for these different results. We also demonstrated that it was possible to achieve a correct order of thresholds by collapsing the response options. Thus, it may be concluded that the WHODAS 2.0 has better discrimination ability in our sample when reducing the number of response options from five to three. Further studies in elderly populations with poor education are required in order to confirm these findings.

The item thresholds resulting from our final PCM covered the whole range of the continuum. Therefore, the items - recoded in three different response options - are appropriate to differentiate between persons across the whole continuum of disability. However, for low levels of disability only a few thresholds are available, thus permitting only rough differentiations between persons' levels of disability. As the WHODAS 2.0 was originally developed for measuring disability in the general population, it can be expected that it differentiates even less there compared to our study population and thus might not be an appropriate instrument to assess disability in very healthy populations. However, the differentiation of disability levels in the healthiest segment of a population is not especially meaningful, as this subgroup of persons is neither relevant for health care planning nor health policy. In addition, if the original coding of items with five response options could be used for model estimation, more thresholds would be estimated and therefore permit a finer distinction of persons' disability levels, likely also in the lowest levels of disability.

Consistent with Luciano et al. [15] no item showed DIF in terms of sex. This means that the WHODAS 2.0 disability score does not overestimate the level of disability in men compared to women or vice versa. Further DIF analyses showed that the items are also not biased by age, education, marital status, presence of comorbidities, overall health status, and smoking status.

Concurrent validity of the 12-item WHODAS 2.0 has previously been tested by Luciano et al. [13] who compared patients with a first major depressive episode who were on sick leave with those who were working and found significant differences regarding their WHODAS 2.0 scores. Our results support the ability of the 12-item WHODAS 2.0 to discriminate between subgroups of AMI patients which are reported to have worse health 

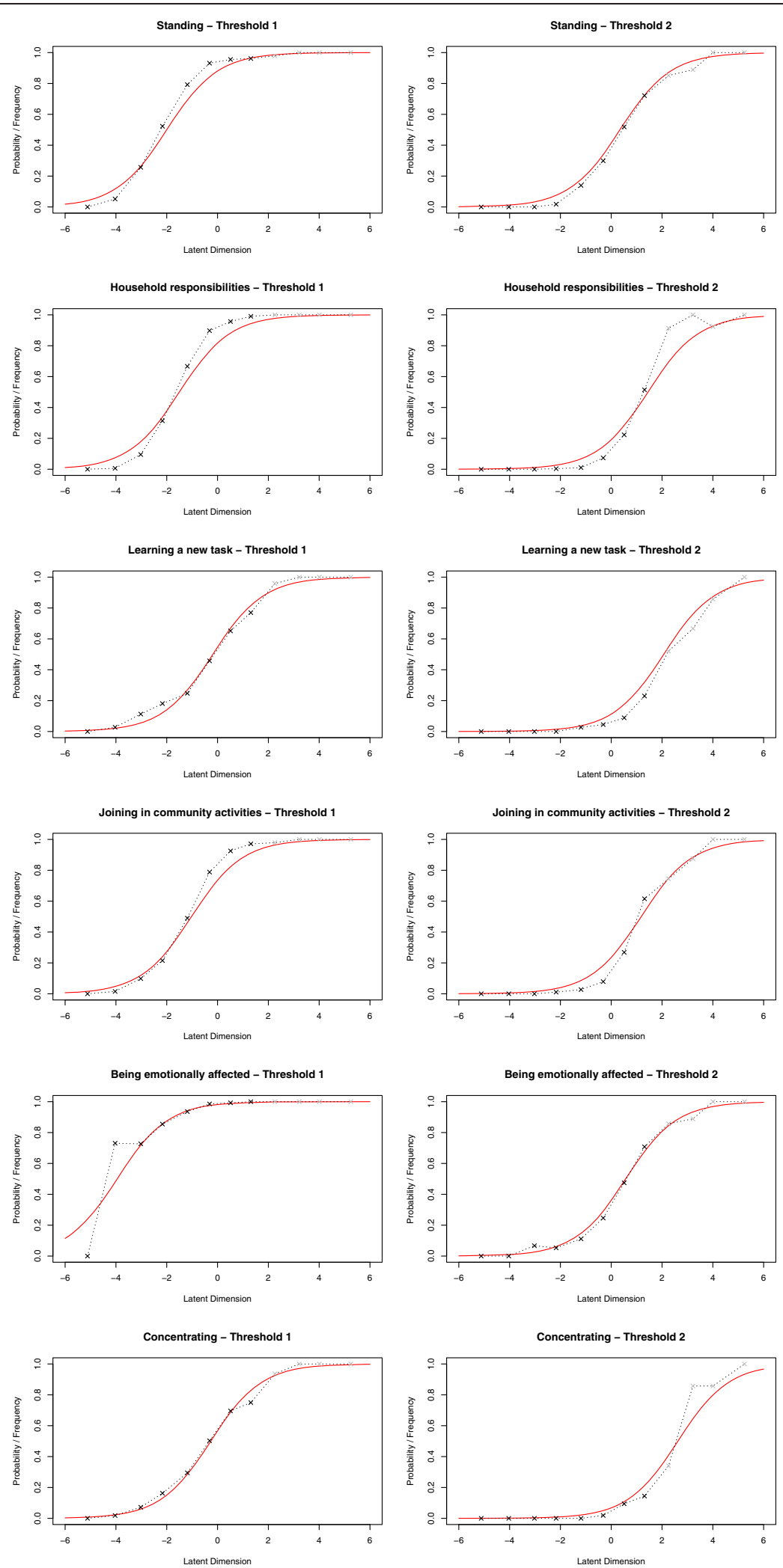

Figure 3 Graphical assessment of item fit: Comparison of 1) expected probabilities for responding above the threshold based on the PCM (red line) and 2) observed response frequencies for groups of persons with close ability estimates (" $x$ "s connected by dotted black line). If the observed frequencies rely on more than 20 persons, the $\mathrm{x}$ is drawn in black, while for smaller groups the $\mathrm{x}$ is grey. 
Table 5 Results on concurrent validity: the linear additive model

\begin{tabular}{llll}
\hline & $\begin{array}{l}\text { Regression } \\
\text { coefficient }\end{array}$ & $\begin{array}{l}\text { Standard } \\
\text { error }\end{array}$ & p-value \\
\hline Intercept & 12.16 & 1.44 & $<0.001$ \\
Sex (male) & -4.28 & 0.96 & $<0.001$ \\
Low education & 1.55 & 0.82 & 0.060 \\
Married & 0.96 & 0.93 & 0.303 \\
Presence of comorbidities & 8.61 & 0.90 & $<0.001$ \\
Very bad/bad health status & 36.82 & 1.36 & $<0.001$ \\
Moderate health status & 19.16 & 0.83 & $<0.001$ \\
\hline
\end{tabular}

outcomes than others, namely persons with comorbidities or worse overall health status $[21,48]$.

To our knowledge, this is the first study that examined feasibility and psychometric properties of the 12-item WHODAS 2.0 in patients with AMI. A strength of our population-based study is the inclusion of a large sample of patients in a defined area and according to defined criteria, with validated AMI, and standardized assessment of demographic and clinical variables. In terms of psychometric analysis, the application of Rasch analysis has a number of advantages compared with classical test theory methods, e.g., its ability to deal with incomplete data, the possibility of testing for DIF in different subgroups, and the interval scale of the resulting metric on which both item difficulty and person ability can be meaningfully compared. Furthermore, parameters of Rasch models generally are neither sample- nor test-dependent, a property which is summarized under the term of specific objectivity [49].

There are some limitations of our study that should be mentioned. The data we based our analyses on solely consist of German patients with AMI. Therefore, the generalization of our results to other patient groups and other settings might be limited. Furthermore, it cannot be excluded that some characteristics (e.g., linguistic and cultural aspects) of the German version of the WHODAS 2.0 could have influenced some of our results.

\section{Conclusions}

Our study demonstrated that the 12-item WHODAS 2.0 self-report form is feasible for application in a sample of persons with AMI that was characterized by a high amount of elderly and poorly educated individuals. Rasch analysis revealed that the 12-item WHODAS 2.0 is a nonbiased instrument with respect to sex, age, marital status, education, presence of comorbidities, overall health status, and smoking status. Its items differentiate

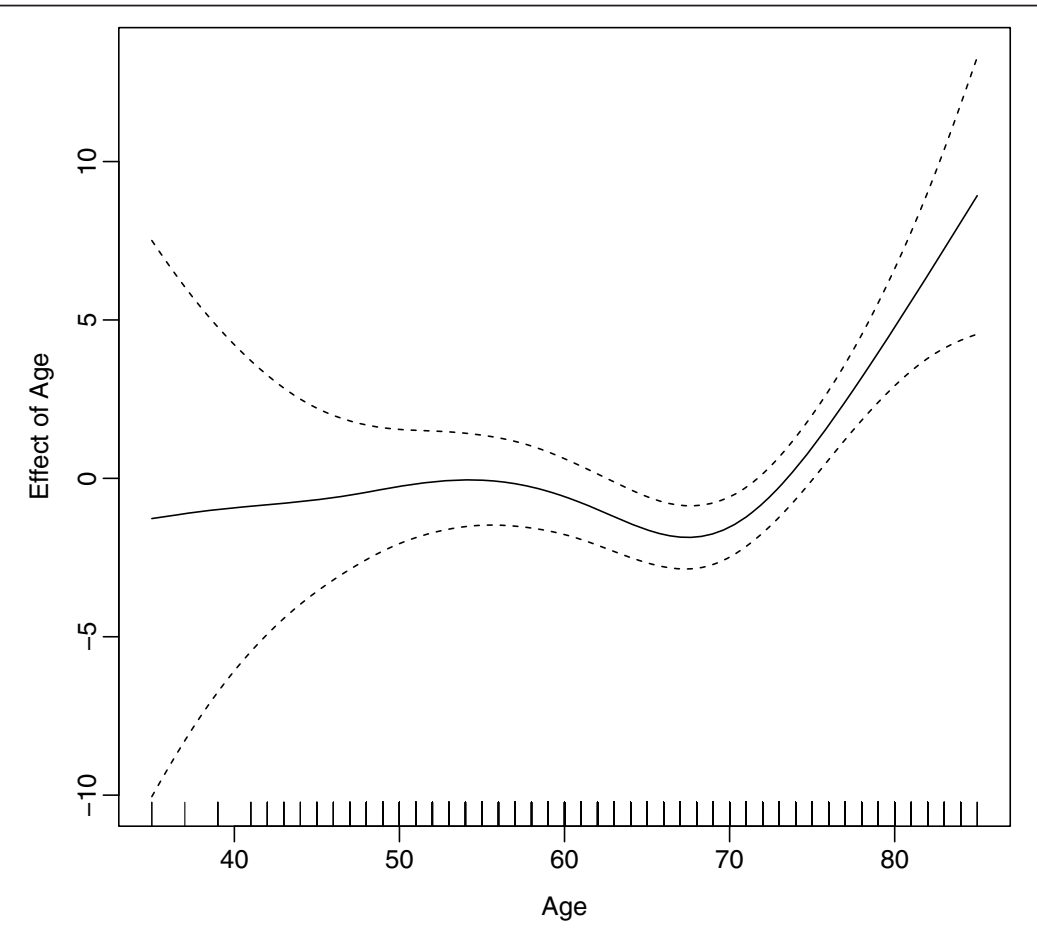

Figure 4 Results on concurrent validity: Nonlinear effect of age (solid line) resulting from the linear additive model and $95 \%$ credible intervals (dashed lines). 
between persons across the whole continuum of disability. Shortcomings refer to the unordered thresholds of most items in our sample, which could be resolved by collapsing of response categories.

\section{Abbreviations}

AMI: Acute myocardial infarction; CHD: Coronary heart disease; DIF: Differential item functioning; EQ5D: EuroQol 5D; ICF: International Classification of Functioning, Disability and Health; PCM: Partial Credit Model; SF-36: Short Form 36 Health Survey; WHODAS: World Health Organization Disability Assessment Schedule.

\section{Competing interests}

The authors declare that they have no competing interests.

\section{Authors' contributions}

IK contributed to conception, design, and coordination of the study, performed the statistical analysis (feasibility), and drafted the manuscript. $\mathrm{KB}$ performed the statistical analysis (psychometric properties) and drafted the manuscript. MC was involved in the conception and design of the study presented in this paper and the revision of the paper. CO was involved in conceptualization of the statistical analysis and supervised the analyses performed. CM is principle investigator, conceived the follow-up study of the KORA Myocardial Infarction Registry and revised the paper. All authors read and approved the final manuscript.

\section{Acknowledgments}

The KORA research platform and the MONICA Augsburg studies were initiated and financed by the Helmholtz Zentrum München, German Research Center for Environmental Health, which is funded by the German Federal Ministry of Education, Science, Research and Technology and by the State of Bavaria. Since the year 2000, the collection of MI data has been cofinanced by the German Federal Ministry of Health to provide population-based MI morbidity data for the official German Health Report (see www.gbe-bund. de). Steering partners of the MONICA/KORA Infarction Registry, Augsburg, include the KORA research platform, Helmholtz Zentrum München and the Department of Internal Medicine I, Cardiology, Central Hospital of Augsburg.

We thank all members of the Helmholtz Zentrum München, Institute of Epidemiology II, and the field staff in Augsburg who were involved in the planning and conduct of the study. We wish to thank the local health departments, the office-based physicians, and the clinicians of the hospitals within the study area for their support. Finally, we express our appreciation to all study participants.

\section{Author details}

'MONICA/KORA Myocardial Infarction Registry, Central Hospital of Augsburg, Stenglinstr. 2, Augsburg 86156, Germany. ${ }^{2}$ Institute of Epidemiology II, Helmholtz Zentrum München, German Research Center for Environmental Health $(\mathrm{GmbH})$, Ingolstädter Landstr. 1, Neuherberg 85764, Germany. ${ }^{3}$ Department of Medical Informatics, Biometry and Epidemiology - IBE, Public Health and Health Services Research, Research Unit for Biopsychosocial Health, Ludwig-Maximilians-University (LMU) Munich, Marchioninistr. 17, Munich 81377, Germany.

\section{Received: 26 February 2014 Accepted: 1 October 2014}

\section{Published online: 10 October 2014}

\section{References}

1. Madden RH, Dune T, Lukersmith S, Hartley S, Kuipers P, Gargett A, Llewellyn G: The relevance of the international classification of functioning, disability and health (ICF) in monitoring and evaluating community-based rehabilitation (CBR). Disabil Rehabil 2014, 36:826-827.

2. Üstün TB, Chatterji S, Kostanjsek N, Rehm J, Kennedy C, Epping-Jordan J, Saxena S, Von Korff M, Pull C, Project WNJ: Developing the world health organization disability assessment schedule 2.0. Bull World Health Organ 2010, 88:815-823.

3. Federici S, Meloni F: WHODAS II: Disability self-evaluation in the ICF conceptual frame. In International Encyclopedia of Rehabilitation. Edited by Stone J, Blouin $M ; 2013$.
4. World Health Organisation: International Classification of Functioning, Disability and Health. Geneva, Switzerland: World Health Organisation; 2001.

5. Üstün TB, Kastanjsek N, Chatterji S, Rehm J: Measuring Health and Disability. Manual for WHO Disability Assessment Schedule. WHODAS 2.0. Geneva: World Health Organization; 2010.

6. Rehm J, Üstün TB, Saxena S, Nelson CB, Chatterji S, Ivis F, Adlaf ED: On the development and psychometric testing of the WHO screening instrument to assess disablement in the general population. Int $J$ Methods Psychiatr Res 1999, 8:110-122.

7. PosI M, Cieza A, Stucki G: Psychometric properties of the WHODASII in rehabilitation patients. Qual Life Res 2007, 16:1521-1531.

8. Schlote A, Richter M, Wunderlich MT, Poppendick U, Moller C, Schwelm K, Wallesch CW: WHODAS II with people after stroke and their relatives. Disabil Rehabil 2009, 31:855-864.

9. Meesters JJ, Verhoef J, Liem IS, Putter H, Vliet Vlieland TP: Validity and responsiveness of the World Health Organization Disability Assessment Schedule II to assess disability in rheumatoid arthritis patients. Rheumatology (Oxford) 2010, 49:326-333.

10. Garin O, Ayuso-Mateos JL, Almansa J, Nieto M, Chatteri S, Vilagut G, Alonso J, Cieza A, Svetskova O, Burger H, Racca V, Francescutti C, Vieta E, Kostanjsek N, Raggi A, Leonardi M, Ferrer M, for the MHADIE consortium: Validation of the "World Health Organization Disability Assessment Schedule, WHODAS-2" in patients with chronic diseases. Health Qual Life Outcomes 2010, 8:51.

11. Andrews $G$, Kemp A, Sunderland M, Von Korff M, Ustün TB: Normative data for the 12 item who disability assessment schedule 2.0. PLoS One 2009, 4:e8343.

12. Sousa RM, Dewey ME, Acosta D, Jotheeswaran AT, Castro-Costa E, Ferri CP, Guerra M, Huang Y, Jacob KS, Rodriguez Pichardo JG, Ramirez NG, Rodriguez JL, Rodriguez MC, Salas A, Sosa AL, Williams J, Prince MJ: Measuring disability across cultures-the psychometric properties of the WHODAS II in older people from seven low- and middle-income countries. The 10/66 Dementia Research Group population-based survey. Int J Methods Psychiatr Res 2010, 19:1-17.

13. Luciano JV, Ayuso-Mateos JL, Fernandez A, Serrano-Blanco A, Roca M, Haro JM: Psychometric properties of the twelve item World Health Organization Disability Assessment Schedule II (WHO-DAS II) in Spanish primary care patients with a first major depressive episode. J Affect Disord 2010, 121:52-58.

14. Luciano JV, Ayuso-Mateos JL, Fernandez A, Aguado J, Serrano-Blanco A, Roca M, Haro JM: Utility of the twelve-item World Health Organization Disability Assessment Schedule II (WHO-DAS II) for discriminating depression "caseness" and severity in Spanish primary care patients. Qual Life Res 2010, 19:97-101.

15. Luciano JV, Ayuso-Mateos JL, Aguado J, Fernandez A, Serrano-Blanco A, Roca M, Haro JM: The 12-item World Health Organization Disability Assessment Schedule II (WHO-DAS II): a nonparametric item response analysis. BMC Med Res Methodol 2010, 10:45.

16. Guccione AA, Felson DT, Anderson JJ, Anthony JM, Zhang Y, Wilson PW, Kelly-Hayes M, Wolf PA, Kreger BE, Kannel WB: The effects of specific medical conditions on the functional limitations of elders in the Framingham Study. Am J Public Health 1994, 84:351-358.

17. Pinsky J, Jette A, Branch L, Kannel W, Feinleib M: The Framingham Disability Study: relationship of various coronary heart disease manifestations to disability in older persons living in the community. Am J Public Health 1990, 80:1363-1367.

18. Dodson JA, Arnold SV, Reid KJ, Gill TM, Rich MW, Masoudi FA, Spertus JA, Krumholz HM, Alexander KP: Physical function and independence 1 year after myocardial infarction: observations from the Translational Research Investigating Underlying disparities in recovery from acute Myocardial infarction: Patients' Health status registry. Am Heart J 2012, 163:790-796.

19. Ades PA, Savage PD, Tischler MD, Poehlman ET, Dee J, Niggel J: Determinants of disability in older coronary patients. Am Heart J 2002, 143:151-156.

20. Rosow I, Breslau N: A Guttman health scale for the aged. J Gerontol 1966, 21:556-559.

21. Plichart M, Barberger-Gateau P, Tzourio C, Amouyel P, Peres K, Ritchie K, Jouven $X$, Ducimetiere P, Empana JP: Disability and incident coronary heart disease in older community-dwelling adults: the Three-City Study. J Am Geriatr Soc 2010, 58:636-642.

22. Whitson HE, Landerman LR, Newman AB, Fried LP, Pieper CF, Cohen HJ: Chronic medical conditions and the sex-based disparity in disability: 
the Cardiovascular Health Study. J Gerontol A Biol Sci Med Sci 2010, 65:1325-1331.

23. Meisinger $\mathrm{C}$, Hormann A, Heier M, Kuch B, Lowel H: Admission blood glucose and adverse outcomes in non-diabetic patients with myocardial infarction in the reperfusion era. Int J Cardiol 2006, 113:229-235.

24. Kuch B, Heier M, Von Scheidt W, Kling B, Hoermann A, Meisinger C: 20-year trends in clinical characteristics, therapy and short-term prognosis in acute myocardial infarction according to presenting electrocardiogram: the MONICA/KORA AMI Registry (1985-2004). J Intern Med 2008, 264:254-264.

25. Sangha O, Stucki G, Liang MH, Fossel AH, Katz JN: The self-administered comorbidity questionnaire: a new method to assess comorbidity for clinical and health services research. Arthritis Rheum 2003, 49:156-163.

26. Bond TG, Fox CM: Applying the Rasch Model. Fundamental Measurement in the Human Sciences. New York: Routledge; 2007.

27. Reise SP: The rediscovery of bifactor measurement models. Multivar Behav Res 2012, 47:667-696.

28. Jennrich RI, Bentler PM: Exploratory bi-factor analysis. Psychometrika 2011, 76:537-549.

29. Buja ANE: Remarks on parallel analysis. Multivar Behav Res 1992, 27:509-540.

30. Reeve BB, Fayers P: Applying item response theory modeling for evaluating questionnaire item and scale properties. In Assessing Quality of Life in Clinical Trials: Methods of Practice. Edited by Fayers P, Hays RD. Oxford: Oxford University Press; 2005:55-73.

31. Tennant A, Conaghan PG: The Rasch measurement model in rheumatology: what is it and why use it? When should it be applied, and what should one look for in a Rasch paper? Arthritis Rheum 2007, 57:1358-1362.

32. Elhan AH, Küçükdeveci AA, Tennant A: The Rasch Measurement Model. In Research Issues in physical and rehabilitation Medicine. Edited by Franchignoni F. Pavia: Maugeri Foundation Books; 2010:89-102.

33. Tesio L: Measuring behaviours and perceptions: Rasch analysis as a tool for rehabilitation research. J Rehabil Med 2003, 35:105-115.

34. Pallant JF, Tennant A: An introduction to the Rasch measurement model: an example using the Hospital Anxiety and Depression Scale (HADS). Br J Clin Psychol 2007, 46:1-18.

35. Smith RM, Schumacker RE, Bush MJ: Using item mean squares to evaluate fit to the Rasch Model. J Outcome Meas 1998, 2:66-78.

36. Smith A, Rush R, Fallowfield L, Velikova G, Sharpe M: Rasch fit statistics and sample size considerations for polytomous data. BMC Med Res Methodol 2008, 8:33.

37. R Core Team: $R$ : A language and environment for statistical computing. Vienna, Austria: R Foundation for Statisctical Computing; 2013.

38. Mair P, Hatzinger R, Maier MJ: eRm: Extended Rasch Modeling; 2012.

39. Choi SW, Gibbons LE, Crane PK: lordif: An R package for detecting differential item functioning using iterative hybrid ordinal logistic regression/item response theory and Monte Carlo simulations. J Stat Softw 2011, 39:1-30

40. Wood SN: Generalized Additive Models. An Introduction with R. Chapmann \& Hall/CRC; 2006

41. Christensen Al, Ekholm O, Glumer C, Juel K: Effect of survey mode on response patterns: comparison of face-to-face and self-administered modes in health surveys. Eur J Public Health 2013.

42. Kirchberger I, Finger T, Muller-Buhl U: A German version of the intermittent claudication questionnaire (ICQ): cultural adaptation and validation. Vasa 2012, 41:333-342.

43. Lim LL, Fisher JD: Use of the 12-item short-form (SF-12) Health Survey in an Australian heart and stroke population. Qual Life Res 1999, 8:1-8.

44. Shah SJ, Krumholz HM, Reid KJ, Rathore SS, Mandawat A, Spertus JA, Ross JS: Financial stress and outcomes after acute myocardial infarction. PLoS One 2012, 7:e47420.

45. Coste J, Quinquis L, Audureau E, Pouchot J: Non response, incomplete and inconsistent responses to self-administered health-related quality of life measures in the general population: patterns, determinants and impact on the validity of estimates - a population-based study in France using the MOS SF-36. Health Qual Life Outcomes 2013, 11:44.

46. Rothman K, Greenland S: Precision and validity in epidemiologic studies In Modern Epidemiology. Edited by Rothman K, Greenland S. Philadelphia: Lippincott Williams \& Wilkins; 1998.

47. Peyre H, Leplege A, Coste J: Missing data methods for dealing with missing items in quality of life questionnaires. A comparison by simulation of personal mean score, full information maximum likelihood, multiple imputation, and hot deck techniques applied to the SF-36 in the French 2003 decennial health survey. Qual Life Res 2011, 20:287-300.

48. Pettersen Kl, Reikvam A, Rollag A, Stavem K: Understanding sex differences in health-related quality of life following myocardial infarction. Int I Cardiol 2008, 130:449-456.

49. Rasch G: On Specific Objectivity: An attempt at formalizing the request for generality and validity of scientific statements. Dan Yearb Philos 1977, 14:58-93.

doi:10.1186/s12963-014-0027-8

Cite this article as: Kirchberger et al.: Feasibility and psychometric properties of the German 12-item WHO Disability Assessment Schedule (WHODAS 2.0) in a population-based sample of patients with myocardial infarction from the MONICA/KORA myocardial infarction registry. Population Health Metrics 2014 12:27.

\section{Submit your next manuscript to BioMed Central and take full advantage of:}

- Convenient online submission

- Thorough peer review

- No space constraints or color figure charges

- Immediate publication on acceptance

- Inclusion in PubMed, CAS, Scopus and Google Scholar

- Research which is freely available for redistribution

Submit your manuscript at www.biomedcentral.com/submit
C Biomed Central 